\title{
Open government in research
}

SIR - The Medical Research Council (MRC), in appearing to prevent persons receiving its support from taking part in a debate on a matter of scientific uncertainty and public concern, has done itself a disservice and lost public sympathy by implying that the scientific, social and ethical bases of its operations are not matters for public scrutiny.

But what can be done by researchers (scientific or medical) to ensure in such circumstances that the public interest is properly served? We must take as our premise that the public interest requires full and unfettered discussion of all the issues. Clearly an employer threatening, however covertly, the livelihood or scientific career of anyone expressing dissenting views is acting improperly. Nevertheless it is the whole scientific community which is to be blamed if the individual sets those factors higher than public conscience, scientific integrity and professional standards.

In this particular instance, involving the merit of clinical trials to establish the efficacy of folic acid supplement in reducing the risk of spina bifida, $M R C$ an organ of public policy - is going directly against standards of conduct explicitly adopted for governmental organizations by this country and set out in "Recommendation to Member States on the Status of Scientific Researchers" agreed by the General Assembly of UNESCO in 1974. In this at Paragraph 37 we find: "Member States should, in consultation with scientific researchers' organizations and as a matter of standard practice, encourage the employers of scientific researchers, and themselves as employers seek: (a) to regard it as the norm that scientific researchers be at liberty and encouraged to publish the results of their work; (b) to minimize the restrictions placed upon scientific researchers' right to publish their findings, consistent with public interest"'. Further, at Paragraph 34: ". . . Member States should seek to ensure that scientific researchers may: (a) receive without hindrance the questions, criticisms and suggestions addressed to them by their colleagues... a as well as the intellectual stimulus afforded by such communications and the exchanges to which they give rise". In even more specific vein the 1979 Annual Report of the American Association for the Advancement of Science's Committee on Scientific Freedom and Responsibility: "... silencing dissenters as bearers of illtidings may seem in the short term to be the simplest way to deal with the difficult problems which they raise. But in the longer term enhancing the professionalism of scientists and engineers, and defence of their integrity when following its dictates, are vital to the welfare of our entire society" (p.65).

In the dynamic tension of a pluralistic scientific enterprise responsive to sociopolitical priorities one key force is evidently missing from the United Kingdom. This is a body for researchers capable of formulating, expressing and upholding by force of consensus professional standards in research. Such standards should be upheld both by expressing disapproval of bad practice and by support of those who are pressured towards bad practice. It is a long-term objective of my association to create such a body.

J.P. DICKINSON (Chairman)

The Association of Researchers in Medicine and Science Ltd, Leeds, UK

\section{Folic acid deficiency}

SIR - Discussion of folic acid deficiency and spina bifida ( Nature 300, 302-310, 396; 1982) provokes the comment that the existence of folic acid was first uncovered by the findings of Lucy Wills ${ }^{l}$, a British physician, that pregnant women in India developed a deficiency on inadequate diets. Following the synthesis of folic acid, the requirement for it was shown to be increased by pregnancy, and deficiencies of folic acid in pregnant women are regarded as worldwide in scope. "Natural" sources of folic acid, because they usually exist as conjugates, are often less biologically available than the synthetic product. An added impetus to providing pregnant women with folic acid came when Hogan and co-workers ${ }^{3}$ found hydrocephalus in rats born to mothers on a diet deficient in folic acid, and Nelson et al. ${ }^{4}$ reported that multiple congenital abnormalities in young rats were produced by maternal folic acid deficiency during gestation. There is no need for overdosage, and the recommended daily allowance (in the United States) for folic acid in pregnancy is $0.8 \mathrm{mg}$, corresponding to a bulk folic acid cost of less than one-tenth of one cent.

Introduction of folic acid in vitamin products was strongly opposed by some haematologists because large doses given to patients with pernicious anaemia in relapse allowed their neurological symptoms to progress while haematological remission took place. The US Food and Drug Administration maintained restrictions on folic acid for many years because of this. The neurological symptoms did not occur if vitamin $B_{12}$ was administered simultaneously ${ }^{5}$. The biochemical aetiology of this effect depends on the interrelationship of folic acid and vitamin $B_{12}$ in methyl group synthesis and transfer ${ }^{6}$. Aggravation of neurological symptoms by large doses of folic acid could conceivably occur in a pregnant woman with pernicious anaemia if she were not given vitamin $B_{12}$, but this concatenation of circumstances should be rare. In contrast, it is likely that many pregnant women have been deprived of their need for folic acid, which is at borderline levels in many diets, by this caveat.

It is encouraging to read, at long last, that Members of Parliament are asking why their constituents are being "denied an apparently effective treatment", including folic acid. Whether folic acid deficiency is responsible for some cases of spina bifida is not clear, but it seems obvious that pregnant women should receive their requirement for folic acid.

THOMAS H. JUKES

Department of Biophysics and

Medical Physics,

University of California, Berkeley, California, USA

I. Wills, L. Br. med. J. 1, 1059 (1931).

2. Angier, R.B. et al. Science 103, 667 (1946).

3. Hogan, A.G. et al. Proc. Soc. exp. Biol. Med. 74, 293 (1950).

4. Nelson, M.M. et al. J. Nutr. 48, 61 (1952).

5. Jukes, T.H. Int. Rev. Vitam. Res. 23, 356 (1952).

6. Jukes, T.H. Trends biochem. Sci. 5, 112 (1980).

\section{Soviet}

\section{mathematicians}

SIR - I should like to comment briefly on the decline in the number of citations to the Soviet mathematical literature by US mathematicians, noted on p.568 of your issue of 14 October 1982. The explanation is closer to hand, and simpler, than your writer suggests.

Beginning in the late 1960s, Soviet discrimination against political undesirables and Jews has been particularly blatant in the field of mathematics. Students whose parents fall into either one of these categories were denied admission to the best mathematics departments in the Soviet Union, and are currently prevented from attending university at all. Students whose background is considered undesirable and Jewish students, who managed to obtain undergraduate degrees, have encountered increasing difficulty in obtaining graduate degrees. Many mature mathematicians have been prevented from publishing in the more prestigious Russian mathematical journals and even from publishing at all. The journal Matematicheskii Sbornik is the worst offender in this regard.

These policies of the Soviet government have led a substantial number of the best Russian mathematicians to leave the Soviet Union. This, in addition to the policies described above, has resulted in a serious deterioration of the Soviet mathematical literature, which, of course, accounts for the drop in the number of citations.

ALEX ROSENBERG

Department of Mathematics,

Cornell University,

Ithaca, New York, USA

\section{Darwin's blood group}

IN the correspondence "Grouping Darwin" ( Nature 300, 573; 1982), the following corrections should be made to the table of likelihoods: for 43 read 34, for 19 read 18 . 